\title{
НОВЫЙ ПОДХОД К ОЦЕНКЕ РЕЗУЛЬТАТОВ ГИДРАВЛИЧЕСКОГО РАЗРЫВА ПЛАСТА (НА ПРИМЕРЕ БОБРИКОВСКОЙ ЗАЛЕЖИ ШЕРШНЕВСКОГО МЕСТОРОЖДЕНИЯ)
}

\author{
Галкин Владислав Игнатьевич1, \\ vgalkin@pstu.ru
}

\section{Пономарева Инна Николаевна' permpolitech@gmail.com}

\author{
Черепанов Сергей Сергеевич², \\ sergej.s.cherepanov@lukoil.com
}

\section{Филиппов Евгений Владимирович2 evgenii.filippov@lp.lukoil.com}

\author{
Мартюшев Дмитрий Александрович1, \\ martyushevd@inbox.ru \\ 1 Пермский национальный исследовательский политехнический университет, \\ Россия, 614990, г. Пермь, пр. Комсомольский, 29. \\ 2 ООО «ЛУКОЙЛ-ПЕРМЬ», \\ Россия, 614990, г. Пермь, ул. Ленина, 62.
}

\begin{abstract}
Актуальность исследования обусловлена значительным вкладом объемов нефти, добытых в результате проведения на скважинах гидравлического разрыва пласта, в суммарную добычу. Правильная оценка результатов фрактически проведенных мероприятий по гидравлическому разрыву позволит выработать четкие рекомендации по дальнейшему применению данного метода интенсификации добычи нефрти для геолого-физических условий конкретных месторождений.

Цель: оценить результаты проведения гидравлического разрыва пласта применительно к элементу системы разработки, в котором находится скважина - объект воздействия.

объекты: нефтедобывающие скважины - элемент системы разработки бобриковской залежи Шершневского нефртяного месторождения.

Методы: геолого-промысловые исследования, корреляционный анализ, схематизация взаимодействия между скважинами. Результаты. Установлено, что проведение гидравлического разрыва пласта на скважине 221 Шершневского месторождения привело к изменению характера взаимодействия между скважинами в пределах всего элемента системы разработки, который стал работать как единая однонаправленно согласованная система. В результате гидравлического разрыва пласта произошло не просто перераспределение объемов дренирования, а возник синергетический эффрект, когда проведение мероприятия в одной скважине привело к росту дебитов и согласованности работы всего элемента системы разработки. Вероятно, проведение гидравлического разрыва пласта в скважине 221 привело к существенному изменению фрильтрационных параметров бобриковской залежи Шершневского месторождения в более значительных пределах, нежели объем зоны дренирования этой скважины, и на довольно большом участке залежи возникла целая система каналов с пониженными фильтрационными сопротивлениями, а не единичная трещина, как это принято в классическом представлении.
\end{abstract}

\section{Ключевые слова:}

Гидравлический разрыв пласта, терригенный коллектор, взаимодействие между скважинами, корреляция дебитов, метод увеличения нефтеотдачи.

\section{Введение}

Гидравлический разрыв пласта (ГРП) в настоящее время является одним из эффективных методов интенсификации добычи нефти во всем мире. Адекватная оценка результатов проведенных ГРП позволяет, в том числе, оценивать перспективы метода в тех или иных геологических условиях.

На территории Пермского края применяются самые разнообразные технологии проведения ГРП, такие как классический проппантный в терригенных коллекторах, кислотный - в карбонатных, кислотный ГРП с закреплением трещин проппантом, азотно-пенный ГРП и др. [1-4]. Эффективность этих технологий обычно оценивают по приросту дебита нефти на скважинах - объектах воздействия. Помимо прироста дебита, в ряде случаев используют также такие показатели технологической эффективности, как дополнительная добыча нефти и продолжительность эффекта, вычисляя эти показатели также применительно к скважинам, на которых ГРП был проведен [5-10]. Такой подход к оценке результатов ГРП обусловлен тем, что данный вид воздействия на пласт принято относить к группе технологий интенсификации притока к скважинам. В частности, в [11-16] сказано, что гидравлический разрыв проводят с целью повышения проницаемости коллектора в призабойной зоне и увеличения производительности скважины. Однако некоторые исследователи [17-23] считают, что ГРП в определенных условиях является не только способом увеличения проницаемости призабойной зоны и, как следствие, продуктивности конкретной скважины, но и глубокопроникающим методом воздействия на продуктивные пласты в целом. 
Таблица 1. Краткая информация о скважине - объекте ГРП

Table 1. Summary of the borehole-hydraulic fracturing site

\begin{tabular}{|c|c|}
\hline $\begin{array}{l}\text { Наименование показателя, ед. изм. } \\
\text { Parameter, measurement unit }\end{array}$ & $\begin{array}{c}\text { Значение } \\
\text { Value }\end{array}$ \\
\hline $\begin{array}{l}\text { Абсолютная отметка кровли, м } \\
\text { Absolute roof mark, m }\end{array}$ & -1846 \\
\hline $\begin{array}{l}\text { Эффективная нефтенасыщенная толщина, м } \\
\text { Effective net payable thickness, m }\end{array}$ & 9,9 \\
\hline $\begin{array}{l}\text { Вязкость пластовой нефти, мПа*с } \\
\text { Viscosity of reservoir oil, MPa*s }\end{array}$ & 3,19 \\
\hline $\begin{array}{l}\text { Газонасыщенность пластовой нефти, } \mathrm{m}^{3} / \mathrm{T} \\
\text { Gas saturation of reservoir oil, } \mathrm{m}^{3} / \mathrm{t}\end{array}$ & 64,2 \\
\hline $\begin{array}{l}\text { Давление насыщения нефти газом, МПа } \\
\text { Pressure of oil gas saturation, MPa }\end{array}$ & 11,94 \\
\hline $\begin{array}{l}\text { Коэффициент пористости, д. ед. } \\
\text { Porosity factor, fraction of units }\end{array}$ & 0,17 \\
\hline $\begin{array}{l}\text { Коэффициент песчанистости, д. ед. } \\
\text { Sandiness coefficient, fraction of units }\end{array}$ & 0,6 \\
\hline $\begin{array}{l}\text { Расчлененность, д. ед. } \\
\text { Dismemberment, fraction of units }\end{array}$ & 3,21 \\
\hline $\begin{array}{l}\text { Коэффициент проницаемости }{ }^{*}, \text { мкм }^{2} \\
\text { Permeability coefficient*, } \mu \mathrm{m}^{2}\end{array}$ & 0,096 \\
\hline $\begin{array}{l}\text { Обводненность продукции до ГРП, \% } \\
\text { Water cut before hydraulic fracturing, \% }\end{array}$ & 1 \\
\hline $\begin{array}{l}\text { Забойное давление до ГРП, МПа } \\
\text { Bottom pressure before hydraulic fracturing, MPa }\end{array}$ & 9,55 \\
\hline $\begin{array}{l}\text { Пластовое давление до ГРП, МПа } \\
\text { Reservoir pressure before hydraulic fracturing, } \mathrm{MPa}\end{array}$ & 12,97 \\
\hline
\end{tabular}

*Примечание: коэффициент пронииаемости определен по данным гидродинамических исследований перед ГРП. *Note: permeability coefficient determined by hydrodynamic studies before hydraulic fracturing.

\section{Общие сведения об объекте исследования}

В настоящей статье приводятся сведения о результатах ГРП, проведенного в октябре 2011 г. на скважине 221 Шершневского нефтяного месторождения (Пермский край). Скважина эксплуатирует терригенную бобриковскую залежь, её характерным признаком является размещение практически в центральной части структуры. Отложения бобриковского горизонта представлены преимущественно песчаниками кварцевыми, иногда с прослоями аргиллитов и алевролитов неравномерно глинистых, участками сильно песчанистых до перехода в песчаник. Песчаники, разнозернистые с различными нефтепроявлениями от выпотов нефти по порам до полного нефтенасыщения, можно отнести к русловому аллювию, к которому и приурочена промышленная нефтеносность. Краткие сведения о геолого-физической характери- стике объекта разработки и параметрах работы скважины представлены в табл. 1. Информация о других шести нефтедобывающих скважинах, участвующих в оценке влияния ГРП, представлена в табл. 2.

Стандартные подходы к определению технологической эффективности геолого-технических мероприятий позволили оценить результаты ГРП на данной скважине как весьма высокие для региона. Дебит скважины увеличился практически в три раза, эффект сохранялся на протяжении более чем 2000 сут.

В данной статье выполнено исследование, нацеленное на изучение влияния проведения гидроразрыва не только на показатели эксплуатации самой скважины - объекта ГРП, но и на окружающие скважины, то есть на элемент системы разработки [24-29]. Так, в непосредственной близости от рассматриваемой в статье скважины 221 расположены шесть добывающих скважин (№№ 64, 214, 215, 222, 228 и 229), совместно образующих условный первый кольцевой ряд (рис. 1). На рис. 2 представлена карта распределения плотности остаточных извлекаемых запасов для рассматриваемого элемента разработки на момент проведения ГРП.

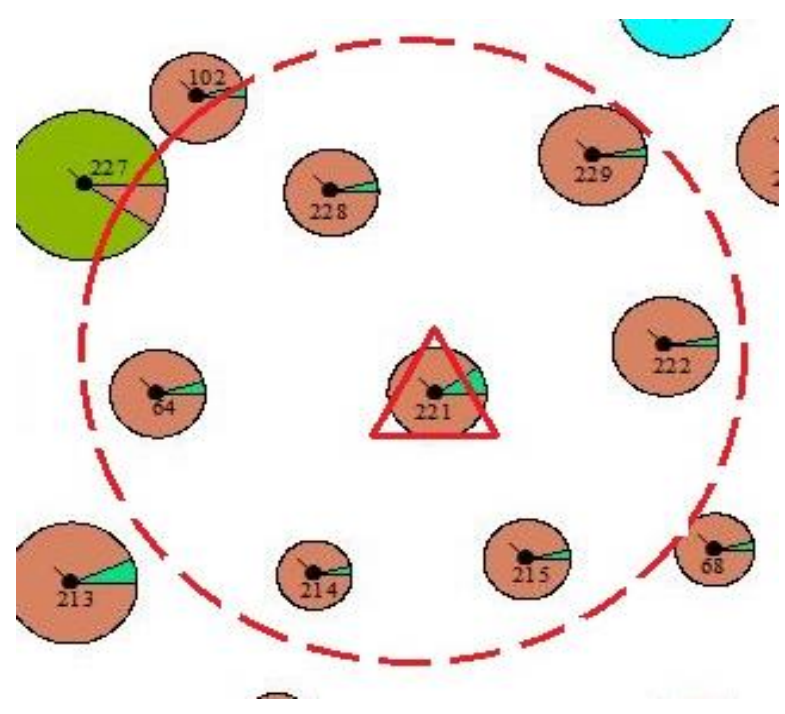

Pис. 1. Схема элемента системы разработки бобриковской залежи Шериневского месторождения

Fig. 1. Diagram of the element of the development system of Bobrikovsky deposits of Shershnevsky field

Таблица 2. Краткая информация о параметрах работы соседних скважин, участвующих в оценке влияния ГРП

Table 2. Brief information on operating parameters of neighboring wells participating in evaluation of the effect of hydraulic fracturing

\begin{tabular}{|c|c|c|c|c|c|}
\hline $\begin{array}{l}\text { № сква- } \\
\text { жины } \\
\text { Wells }\end{array}$ & $\begin{array}{c}\text { Коэффициент прони- } \\
\text { цаемости, мкм² } \\
\text { Permeability } \\
\text { coefficient, } \mu \mathrm{m}^{2}\end{array}$ & $\begin{array}{c}\text { Эффективная нефтенасы- } \\
\text { щенная толщина, м } \\
\text { Effective net payable } \\
\text { thickness, m }\end{array}$ & \begin{tabular}{|c|} 
Пластовое давление до \\
ГРП, МПа \\
Reservoir pressure \\
before hydraulic \\
fracturing, MPa
\end{tabular} & $\begin{array}{c}\text { Забойное давление до } \\
\text { ГРП, МПа } \\
\text { Bottom pressure before } \\
\text { hydraulic fracturing, } \\
\text { МРа }\end{array}$ & $\begin{array}{c}\text { Обводненность про- } \\
\text { дукции до ГРП, \% } \\
\text { Water cut before hy- } \\
\text { draulic fracturing, \% }\end{array}$ \\
\hline 215 & 0,909 & 8,7 & 11,59 & 10,25 & 1,0 \\
\hline 222 & 0,206 & 10,8 & 12,92 & 10,06 & 0 \\
\hline 229 & 1,716 & 11,2 & 11,21 & 9,79 & 0 \\
\hline 228 & 0,111 & 14,7 & 12,78 & 11,76 & 2,0 \\
\hline 64 & 0,456 & 5,4 & 13,10 & 11,71 & 3,0 \\
\hline 214 & 0,078 & 12,6 & 12,77 & 9,77 & 5,0 \\
\hline
\end{tabular}




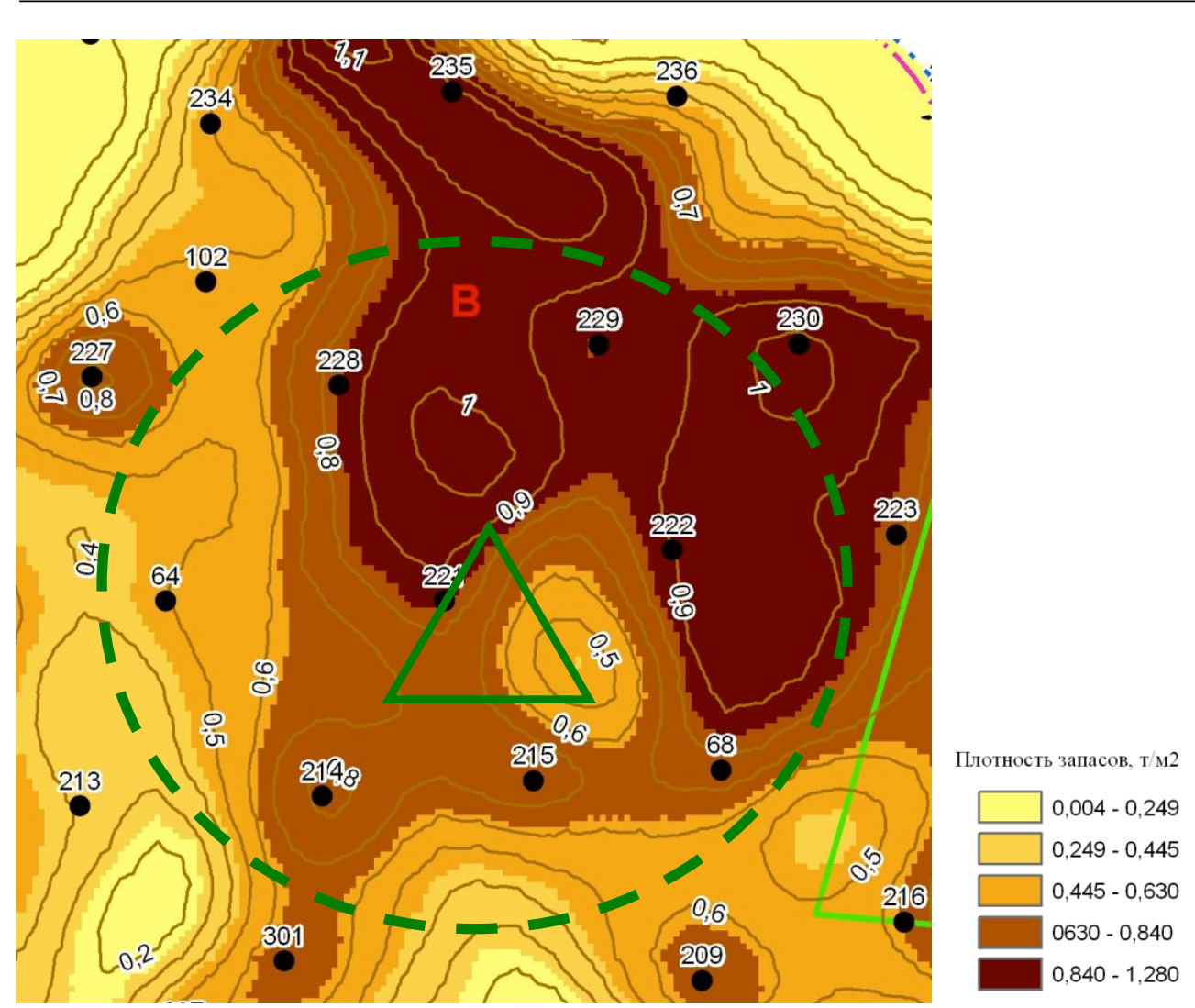

Pис. 2. Схема элемента системь разработки бобриковской залежи Шериневского месторождения с распределением плотности подвижных запасов на момент проведения ГРП

Fig. 2. Diagram of an element of the Bobrikovsky deposits development system at the Shershnevsky field with distribution of mobile reserves density at hydraulic fracturing

\section{Исследование взаимодействия между скважинами до и после проведения ГРП}

Очевидно, если гидроразрыв пласта, выполненный в скважине 221, имел глубокопроникающий характер, о чем косвенно свидетельствуют высокие значения показателей технологической эффективности, ближайшие добывающие скважины должны «отреагировать» изменением значений своих показателей эксплуатации. Для проверки данной гипотезы привлечены и проанализированы промысловые материалы дебиты нефти и жидкости, а также накопленные значения добычи нефти и жидкости по всем скважинам выделенного элемента разработки.

На первом этапе выполнено сопоставление показателей эксплуатации в периоды до и после ГРП. При этом показатели до ГРП отнесены к классу 1 (выборка составила $n=69$ значений), после ГРП - к классу 2 $(\mathrm{n}=81$ значение). Сравнение средних значений дебитов жидкости для классов 1 и 2, то есть до и после ГРП, выполнено с использованием инструментов математической статистики (t-критерия Стьюдента и $\chi^{2}$ критерия Пирсона), результаты сравнения приведены в табл. 3.

Представленные в таблице данные статистически подтверждают изменение (увеличение) дебитов жидкости после проведения ГРП для всех скважин выделенного элемента системы разработки, а не только для скважины 221 - объекта проведенного ГРП.
Таблица 3. Сравнение средних значений дебитов жидкости $\left(\mathrm{m}^{3} /\right.$ сутки) до и после ГРП для скважин выделенного элемента системы разработки

Table 3. Comparison of the average values of fluid production rates $\left(\mathrm{m}^{3} /\right.$ day) before and after fracturing for well development system selected element

\begin{tabular}{|c|c|c|c|c|}
\hline \multirow{2}{*}{ 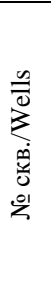 } & \multicolumn{2}{|c|}{$\begin{array}{c}\text { Статистические характеристики } \\
\text { показателей } \\
\text { Statistical characteristics } \\
\text { of indicators } \\
\end{array}$} & \multicolumn{2}{|c|}{$\begin{array}{l}\text { Критерий сравнения" } \\
\text { Comparison criterion }\end{array}$} \\
\hline & $\begin{array}{c}\text { Класс 1 } \\
\text { (до ГРП) } \\
\text { Class 1 } \\
\text { (before hydraulic } \\
\text { fracturing) }\end{array}$ & \begin{tabular}{|c|} 
Класс 2 \\
(после ГРП) \\
Class 2 \\
(after hydraulic \\
fracturing) \\
\end{tabular} & $\begin{array}{c}\text { Стьюдента } \\
\text { Styudent }\end{array}$ & $\begin{array}{l}\text { Пирсона } \\
\text { Pearson }\end{array}$ \\
\hline 64 & $21,9 \pm 17,6$ & $48,1 \pm 12,1$ & $\frac{-10,724}{0,000}$ & $\frac{85,483}{0,000}$ \\
\hline 214 & $13,8 \pm 13,7$ & $22,9 \pm 3,7$ & $\frac{-5,773}{0,000}$ & $\frac{36,027}{0,000}$ \\
\hline 215 & $29,1 \pm 14,4$ & $37,4 \pm 5,0$ & $\frac{-4,833}{0,000}$ & $\frac{29,127}{0,014}$ \\
\hline 222 & $36,1 \pm 15,9$ & $60,3 \pm 8,9$ & $\frac{-11,681}{0,000}$ & $\frac{135,111}{0,014}$ \\
\hline 228 & $30,5 \pm 6,6$ & $43,7 \pm 3,9$ & $\frac{-14,997}{0,000}$ & $\frac{134,260}{0,000}$ \\
\hline 229 & $47,6 \pm 12,9$ & $55,9 \pm 5,8$ & $\frac{-5,228}{0,000}$ & $\frac{24,509}{0,014}$ \\
\hline
\end{tabular}

"Примечание: в числителе приведено значение критерия, в знаменателе - уровень его значимости.

*Note: the numerator shows the value of the criterion, in the denominator - the level of its importance. 
Аналогичный вывод получен также при сравнении дебитов нефти, накопленной добычи нефти и жидкости, характерных для периодов эксплуатации до и после ГРП. Проведение ГРП на скважине 221 привело к увеличению не только ее дебита, но и дебитов всех соседних, расположенных в непосредственной близости, скважин. Проведенное ГРП на скважине 221 нельзя рассматривать как геолого-техническое мероприятие, направленное только лишь на интенсификацию притока непосредственно к этой скважине. Также следует отметить, что во всех случаях причиной прироста не явилось проведение каких-либо геологотехнических мероприятий. Предположение о том, что в результате ГРП происходит простое перераспределение объемов дренирования между соседними скважинами в пользу скважины-объекта воздействия, также не является правильным, поскольку в этом случае имело бы место снижение дебитов соседних скважин.

На следующем этапе исследования выполнена оценка взаимного влияния скважин, с этой целью использованы инструменты корреляционного анализа. Результаты исследования в виде корреляционных матриц, характеризующих взаимную связь между дебитами нефти, приведены в табл. 4.

С целью визуализации полученных результатов построены схемы изменения коэффициентов корре- ляции между дебитами нефти в пределах элемента разработки до (рис. 3) и после ГРП (рис. 4).

Таблица 4. Корреляционная матрица между значениями дебитов нефти скважин выделенного элемента разработки (числитель - до ГРП, знаменатель - после ГРП)

Table 4. Correlation matrix between the values of oil flow rates of wells of the selected design element (numerator - before fracturing, denominator-after fracturing)

\begin{tabular}{|c|c|c|c|c|c|c|c|}
\hline $\begin{array}{c}\text { Скважины } \\
\text { Wells }\end{array}$ & 221 & 64 & 214 & 215 & 222 & 228 & 229 \\
\hline 221 & $\frac{1,00}{100}$ & $-0,10$ & $\underline{0,65^{*}}$ & $-0,72^{*}$ & $\frac{-0,81^{*}}{064 *}$ & $\frac{0,24 *}{0,6 * *}$ & $\begin{array}{l}-0,17 \\
0,54 *\end{array}$ \\
\hline 64 & & $\frac{1,00}{1,00}$ & $0,57 *$ & $\frac{-0,29 *}{0,83^{*}}$ & $\frac{-0,23}{0,67^{*}}$ & $\frac{-0,05}{0,72 *}$ & $\frac{-0,52^{*}}{0,73^{*}}$ \\
\hline 214 & & & $\frac{1,00}{1,00}$ & $\frac{-0,74 *}{0,82 *}$ & $\frac{-0,74^{*}}{0,72^{*}}$ & $\frac{0,13}{0,76^{*}}$ & $\frac{-0,45^{*}}{0,81^{*}}$ \\
\hline 215 & & & & $\frac{1,00}{1,00}$ & $\frac{0,82^{*}}{0,75^{*}}$ & $\frac{-0,02}{0,69^{*}}$ & $\underline{0,32^{*}}$ \\
\hline 222 & & & & & $\frac{1,00}{1,00}$ & $\frac{-0,08}{0,53 *}$ & $\frac{0,38^{*}}{0,74^{*}}$ \\
\hline 228 & & & & & & $\frac{1,00}{1,00}$ & $\frac{-0,13}{0,79 *}$ \\
\hline 229 & & & & & & & $\frac{1,00}{1,00}$ \\
\hline
\end{tabular}

Примечание: -0,65*-значимые коррелячионные связи. Note: $-0,65^{*}-$ significant correlation.

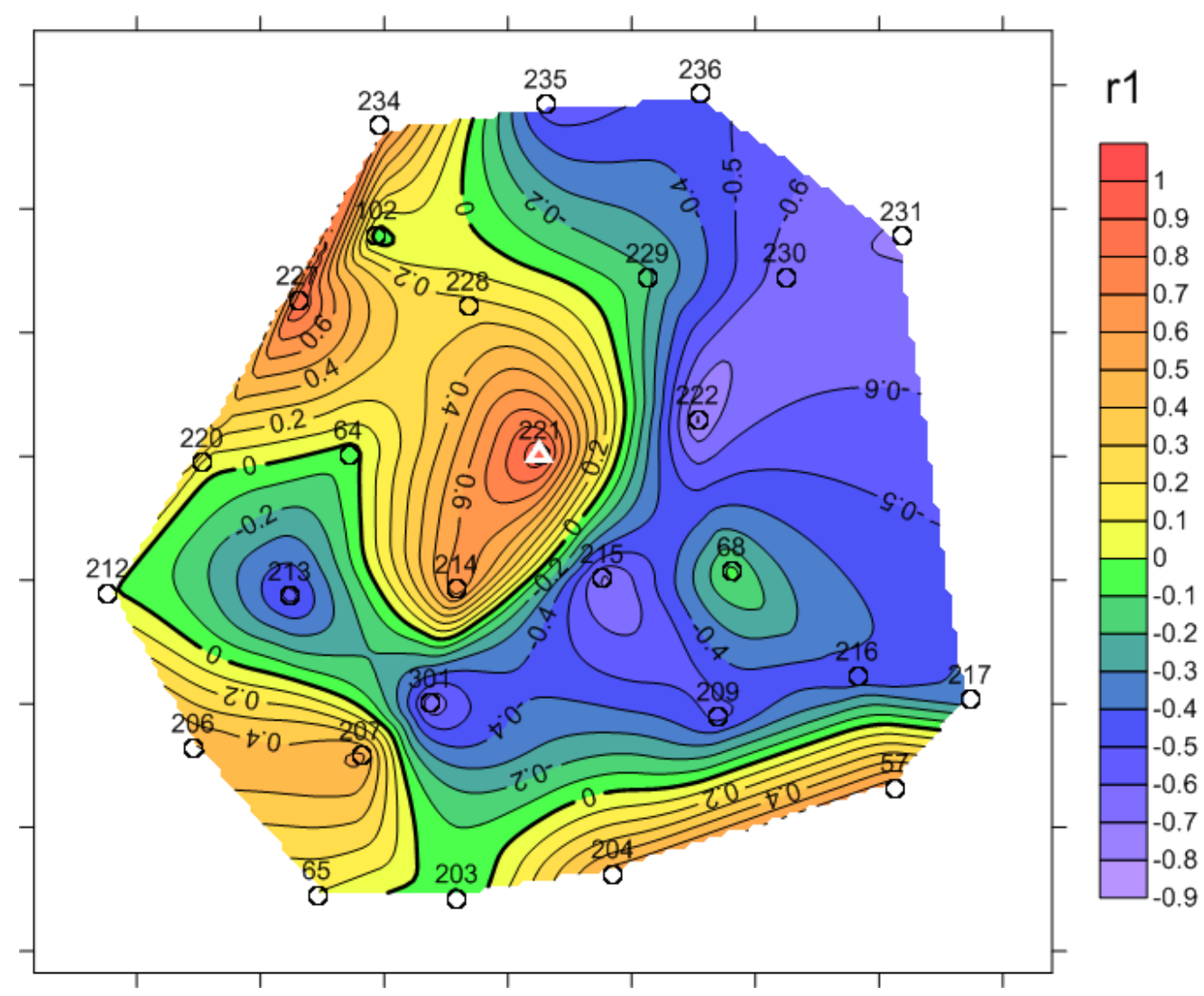

Pис. 3. Схема изменения значений коэффициентов коррелящии между дебитами нефти в пределах элемента разработки до проведения ГРП

Fig. 3. Scheme of changes in the values of correlation coefficients between oil flow rates within the development element before hydraulic fracturing 


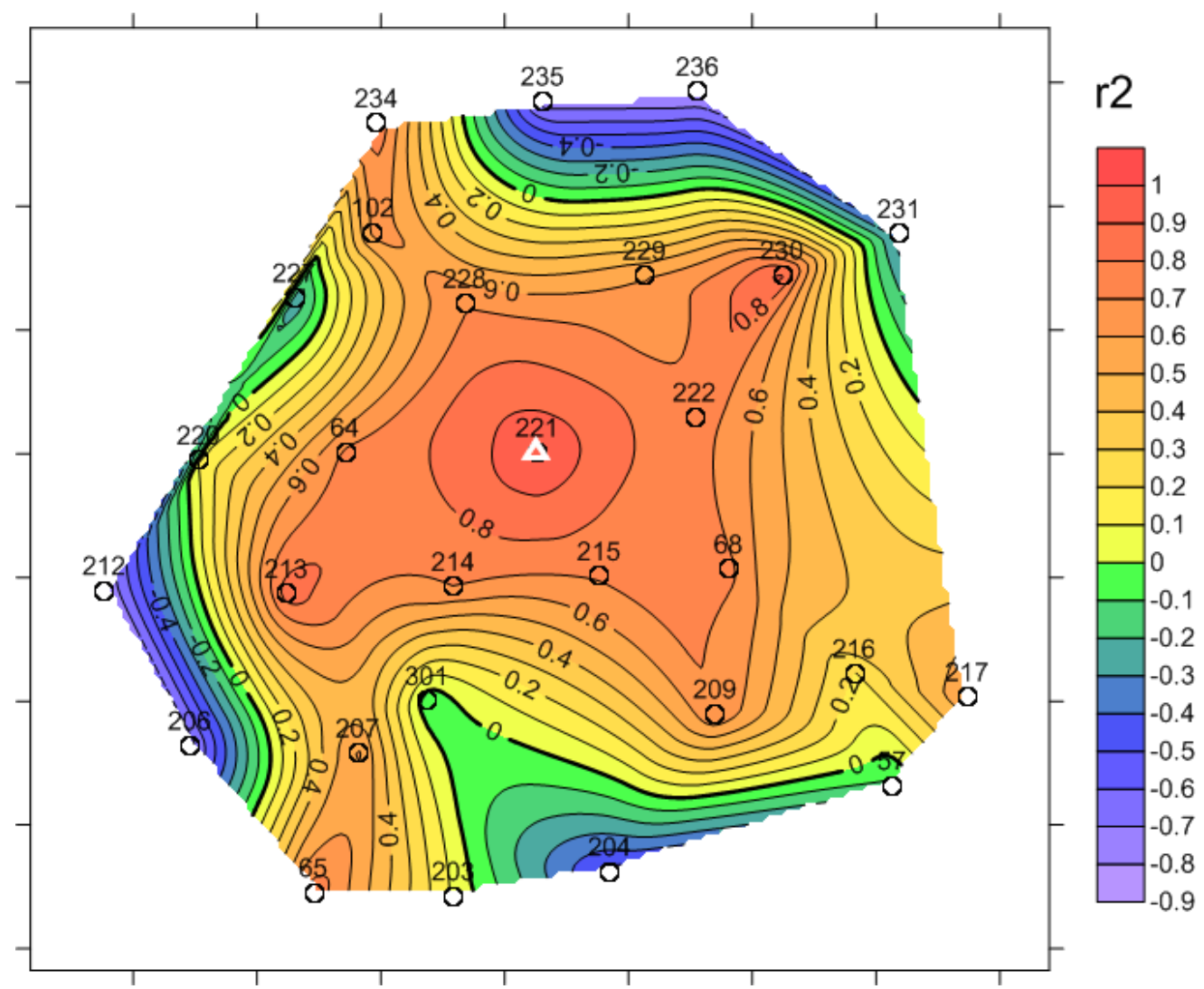

Рис. 4. Схема изменения значений коэффиииентов корреляции между дебитами нефти в пределах элемента разработки после проведения ГРП

Fig. 4. Diagram of changes in the values of the correlation coefficients between oil flow rates within the development element after hydraulic fracturing

Из анализа представленной на рис. 3 схемы следует, что за период, предшествующий ГРП, максимальные положительные корреляции характерны для пары скважин - 221, 214, то есть эти скважины работали согласованно, они синхронно реагировали на какиелибо события однонаправленным изменением своего дебита. Восточная часть выделенного элемента разработки характеризуется довольно сильной отрицательной корреляцией. То есть увеличение дебита скважины 221 приводило к снижению аналогичного показателя в скважинах 215 и 222. Вероятно, увеличение дебитов скважины 221 происходило за счет перераспределения объемов дренирования с восточной части выделенного элемента разработки.

Анализ представленной на рис. 4 схемы демонстрирует существенное изменение в поведении всего выделенного элемента системы разработки в результате проведения ГРП на скважине 221. В пределах первого кольцевого ряда между дебитами всех скважин отмечается значимая положительная корреляция. То есть весь элемент стал работать как единая однонаправленно согласованная система. Положительный характер корреляции свидетельствует о том, что в результате ГРП произошло не просто перераспределение объемов дренирования, а возник синергетический эффект, когда проведение мероприятия в одной скважине привело к росту дебитов и согласованности работы всего элемента системы разработки.

\section{Заключение}

Полученный в ходе исследований вывод свидетельствует о том, что общепринятая модель результата ГРП, заключающаяся в визуализации трещины в пределах зоны дренирования скважины - объекта ГРП, а в некоторых случаях - только в пределах призабойной зоны этой скважины, не отражает картины, произошедшей на бобриковской залежи Шершневского месторождения. Проведение ГРП в скважине 221 привело к существенному изменению фильтрационных параметров бобриковской залежи Шершневского месторождения в более значительных пределах, нежели объем зоны дренирования этой скважины. На довольно большом участке залежи возникла целая система каналов с пониженными фильтрационными сопротивлениями, а не единичная трещина, как это принято в классическом представлении. Применительно к рассматриваемой залежи ГРП следует считать не как единичный, точечный метод интенсификации добычи нефти вследствие увеличения продуктивности скважины - объекта воздействия, а даже, в некоторой степени, как метод увеличения нефтеотдачи.

Безусловно, единичность проведенного исследования не позволяет делать выводов о необходимости пересмотра подходов к оценке результатов ГРП. Представляется целесообразным проведение аналогичных исследований на других скважинах данного и других регионов. 


\section{СПИСОК ЛИТЕРАТУРЫ}

1. Восстановление и повышение продуктивности добывающих скважин каширского и подольского объектов на одном из нефтяных месторождений Пермского края / А.С. Вотинов, С.А. Дроздов, В.Л. Малышева, В.А. Мордвинов // Вестник Пермского национального исследовательского политехнического университета. Геология. Нефтегазовое и горное дело. 2018. - T. 18. - № 2. - C. 140-148.

2. Черепанов С.С., Чумаков Г.Н., Пономарева И.Н. Результаты проведения кислотного гидроразрыва пласта с проппантом на турнейско-фаменской залежи Озерного месторождения // Вестник Пермского национального исследовательского политехнического университета. Геология. Нефтегазовое и горное дело. - 2015. - Т. 14. - № 16. - С. 70-76.

3. Развитие технологий гидравлического разрыва пласта на месторождениях Пермского края / В.Л. Воеводкин, А.А. Алероев, Т.Р. Балдина, А.В. Распопов, А.С. Казанцев, С.А. Кондратьев // Нефтяное хозяйство. - 2018. - № 11. - С. 108-113.

4. Кулакова П.А., Кутлубулатов А.А., Афанасенко В.Г. Прогнозирование эффективности гидравлического разрыва пласта как составляющая оптимизации его дизайна // SOCAR Proceedings. - 2018. - № 2. - C. 41-48.

5. Анализ эффективности технологии гидроразрыва терригенных пластов на Южно-Ромашкинской площади Ромашкинского месторождения в условиях поздней стадии разработки / И.Ф. Галимов, Ф.А. Губайдина, А.В. Вахин, П.В. Исаев // Нефтяное хозяйство. - 2018. - № 1. - С. 52-54.

6. Совершенствование методического подхода к планированию мероприятий по гидроразрыву пласта на нефтяных месторождениях / И.В. Бурениниа, Л.А. Авдеева, М.А. Халикова М.В. Герасимова, И.А. Соловьева // Записки горного института. - 2019. - Т 237. - С. 344-353.

7. Бархатов Э.А., Яркеева Н.Р. Эффективность применения многозонного гидроразрыва пласта в горизонтальных скважинах // Известия Томского политехнического университета. Инжиниринг георесурсов. - 2017. - Т. 328. - № 10. - С. 50-58.

8. Проведение проппантных гидроразрывов низкопроницаемых пластов на нефтяных месторождениях немецкого автономного округа / А.А. Алероев, С.А. Кондратьев, Р.Р. Шарафаев, Д.В. Новокрещенных, В.А. Жигалов // Нефтяное хозяйство. 2017. - № 9. - C. 108-111.

9. Amir Ghaderi, Jaber Taheri-Shakib, Mohamad Amin Sharifnik. The effect of natural fracture on the fluid leak-off in hydraulic fracturing treatment // Petroleum. - March 2019. - V. 5. - Iss. 1. - P. 85-89.

10. Initiation, propagation, closure and morphology of hydraulic fracturing in sandstone cores / Jianming He, Chong Lin, Xiao Li, Yixiang Zhang, Yi Chen // Fuel. - 15 November 2017. - V. 208. - P. 65-70.

11. Мирзаджанзаде А.X. Технология и техника добычи нефти. М.: Недра, 1986. - 382 c.

12. Chukwudi Chukwudozie, Blaise Bourdin, Keita Yoshioka. A variational phase-field model for hydraulic fracturing in porous media // Computer Methods in Applied Mechanics and Engineering. - 15 April 2019. - V. 347. - P. 957-982.

13. Han Yi Wang, Mukul M. Sharma. Modeling of hydraulic fracturing closure on proppants with proppant settling // Journal of Petroleum Science and Engineering. - December 2018. - V. 171. - P. 636-645.

14. Determination of stimulated reservoir volume and anisotropic permeability using analytical modelling of microseismic and hydraulic fracturing parameters / Yew Kwang Yong, Belladonna Maulianda, Sia Chee Wee, Dzeti Mohshim, David Eaton // Journal of Natural Gas Science and Engineering.- October 2018.V. 58. - P. 234-240.

15. A review of the current status of induced seismicity monitoring for hydraulic fracturing in unconventional tight oil and gas reservoirs / Lei Li, Jingqiang Tan, D.A. Wood, Zhengguang Zhao, Haichao Chen // Fuel. - April 2019. - V. 242. - P. 195-210.

16. Three-dimensional lattice simulation of hydraulic fracturing interaction with natural fractures / Wei Fu, A.A. Savitski, B. Damjanac, A.P. Bunger // Computers and Geotechnics. - March 2019. - V. 107. - P. 214-234.

17. Ибрагимов Л.Х., Мищенко И.Т., Челоянц Д.К. Интенсификация добычи нефти. - М.: Наука, 2000. - 414 с.

18. Муслимов Р.Х. Нефтеотдача: прошлое, настоящее, будущее. Казань: Изд-во «Фән» Академии наук РТ, 2014. - 750 с.

19. Оценка эффективности ГРП с учетом образованных геологических тел / Р.3. Нургалиев, Р.И. Галлямов, А.А. Махмутов, Е.В. Корнев, А.В. Астахов // Геология, геофизика и разработка нефтяных и газовых месторождений. - 2017. - № 3. - С. 57-62.

20. Debotyam Maity, Jordan Ciezobka. Using microseismic frequencymagnitude distributions from hydraulic fracturing as an incremental tool for fracture completion diagnostics // Journal of Petroleum Science and Engineering. - May 2019. - V. 176. - P. 1135-1151.

21. Interpretation of the extent of hydraulic fracturing for rockburst prevention using microseismic monitoring data / Quanjie Zhu, Yu Feng, Ming Cai, Jinhai Liu, Honghui Wang // Journal of Natural Gas Science and Engineering. - February 2017. - V. 38. - P. 107-119.

22. Nithin Manohar Rayudu, Xuhai Tang, Gaurav Singh. Simulating three dimensional hydraulic fracturing propagation using displacement correlation method // Tunnelling and Underground Space Technology. - March 2019. - V. 85 - P. 84-91.

23. Hydraulic fracturing in high-temperature granite characterized by acoustic emission / Yuekun Xing, Guangqing Zhang, Tianyu Luo, Yongwang Jiang, Shiwen Ning // Journal of Petroleum Science and Engineering. - July 2019. - V. 178. - P. 475-484.

24. Юдин Е.В., Губанова А.Е., Краснов В.А. Метод оценки интерференции скважин с использованием данных технологических режимов их эксплуатации // Нефтяное хозяйство. 2018. - № 8. - С. 64-69.

25. Особенности влияния интерференции скважин на эффективность гидравлического и газодинамического разрыва пласта / Р.3. Нургалиев, И.Р. Мухлиев, Л.Р. Сагидуллин, И.Ш. Щекатурова, А.А. Рахматуллин // Нефтепромысловое дело. 2018. - № 3. - С. 29-34.

26. Оценка результатов гидравлического разрыва пласта на основе комплексного анализа данных микросейсмического мониторинга и геолого-промысловой информации / А.В. Растегаев, И.А. Черных, И.Н. Пономарева, Д.А. Мартюшев // Нефтяное хозяйство. - 2019. - № 8. - С. 122-125.

27. Impact of the distance between pre-existing fracture and wellbore on hydraulic fracturing propagation / Bo Zhang, Jiyang Liu, S.G. Wang, Shucai Li, Weimin Yang // Journal of Natural Gas Science and Engineering. - September 2018. - V. 57. - P. 155-165.

28. An analysis of tracer flowback profiles to reduce uncertainty in fracture network geometries / Linkai Li, Hanqiao Jiang, Keliu Wu, Junjian Li, Zhangxin Chen // Journal of Petroleum Science and Engineering. - 2019. - V. 173. - P. 246-257.

29. Tarek A. Ganata, Meftah Hrairi. A new choke correlation to predict flow rate of artificially flowing wells // Journal of Petroleum Science and Engineering. - 2018. - V. 171. - P. 1378-1389.

Поступила 12.03.2020 2.

\section{Информация об авторах}

Галкин В.И., доктор геолого-минералогических наук, профессор, заведующий кафедрой геологии нефти и газа Пермского национального исследовательского политехнического университета.

Пономарева И.Н., кандидат технических наук, доцент, доцент кафедры нефтегазовых технологий Пермского национального исследовательского политехнического университета.

Черепанов $\boldsymbol{C}$. $\boldsymbol{C}$., кандидат технических наук, заместитель генерального директора по геологии и разработке ООО «ЛУКОЙЛ-ПЕРМЬ».

Фuлиппов E.B., начальник управления разработки нефтяных и газовых месторождений ООО «ЛУКОЙЛ-ПЕРМЬ».

Мартюшев Д.А., кандидат технических наук, доцент кафедры нефтегазовых технологий Пермского национального исследовательского политехнического университета. 
UDC 622.276 .66

\title{
NEW APPROACH TO THE STUDY OF THE RESULTS OF HYDRAULIC FRACTURING (ON THE EXAMPLE OF BOBRIKOVSKY DEPOSITS OF THE SHERSHNEVSKY FIELD)
}

\author{
Vladislav I. Galkin', \\ vgalkin@pstu.ru \\ Inna N. Ponomareva ${ }^{1}$, \\ permpolitech@gmail.com \\ Sergey S. Cherepanov², \\ sergej.s.cherepanov@lukoil.com \\ Evgeniy V. Filippov², \\ evgenij.filippov@|p.lukoil.com \\ Dmitriy A. Martyushev', \\ martyushevd@inbox.ru \\ 1 Perm National Research Polytechnic University, \\ 29, Komsomolskiy avenue, Perm, 614990, Russia. \\ 2 LLC LUKOIL-PERM, \\ 62, Lenin street, Perm, 614990, Russia.
}

The relevance of the research is caused by significant contribution of oil produced as a result of hydraulic fracturing at the wells to its total production. Correct assessment of the results of actually carried out measures for hydraulic fracturing will make it possible to develop clear recommendations on the further application of this method of intensifying oil production for geological and physical conditions of specific fields.

The main aim of the research is to evaluate the effect of hydraulic fracturing in relation to the element of the development system in which the well is located - the object of impact.

Object: oil producing wells that make up an element of the reservoir development system.

Method: geological field research, correlation analysis, schematization of the interaction between wells.

Results. It was found that the hydraulic fracturing of the well 221 of the Shershnevsky field led to a change in the nature of interaction between the wells within the entire element of the development system, which began to work as a single, unidirectional coordinated system. As a result of hydraulic fracturing, there was no redistribution of drainage volumes, but a synergistic effect arose when holding an event in one well led to an increase in flow rates and consistency of the entire element of the development system. Probably, the conduction of hydraulic fracturing in the well 221 led to a significant change in the reservoir filtration parameters in more significant limits than the volume of the drainage zone of this well, and rather large system of channels with reduced filtration resistance appeared in rather large area of the reservoir, as it is customary in classic presentation.

\section{Key words:}

Hydraulic fracturing, terrigenous reservoir, interaction between wells, correlation of flow rates, method of enhanced oil recovery.

\section{REFERENCES}

1. Votinov A.S., Drozdov S.A., Malysheva V.L., Mordvinov V.A. Restoration and increase of productivity of producing wells of the Kashirsky and Podolsk facilities at one of the oil fields of the Perm Krai. Perm National Research Polytechnic University Bulletin. Geology. Oil and gas and mining, 2018, vol. 18, no. 2, pp. 140-148. In Rus.

2. Cherepanov S.S., Chumakov G.N., Ponomareva I.N. Results of acid fracturing with proppant at the Tournaisian and Famennian deposits of the Ozernoe field. Perm National Research Polytechnic University Bulletin. Geology. Oil and gas and mining, 2015, vol. 14, no. 16, pp. 70-76. In Rus.

3. Voevodkin V.L., Aleroev A.A., Baldina T.R., Raspopov A.V., Kazantsev A.S., Kondratiev S.A. Development of hydraulic fracturing technologies in the fields of the Perm Krai. Oil industry, 2018, no. 11, pp. 108-113. In Rus.

4. Kulakova P.A., Kutlubulatov A.A., Afanasenko V.G. Predicting the effectiveness of hydraulic fracturing as a component of optimizing its design. SOCAR Proceedings, 2018, no. 2, pp. 41-48. In Rus.

5. Galimov I.F., Gubaidina F.A., Vakhin A.V., Isaev P.V. Analysis of the effectiveness of hydraulic fracturing of terrigenous reservoirs in the Yuzhno-Romashkinskaya area of the Romashkinskoe field in the late development stage. Oil Industry, 2018, no. 1, pp. 52-54. In Rus.

6. Bureninia I.V., Avdeeva L.A., Halikova M.A., Gerasimova M.V., Solovieva I.A. Improving the methodological approach to planning measures for hydraulic fracturing in oil fields. Journal of Mining Institute, 2019, vol. 237, pp. 344-353. In Rus.

7. Barkhatov E.A., Yarkeeva N.R. The effectiveness of multi-zone hydraulic fracturing in horizontal wells. Bulletin of the Tomsk Polytechnic University. Geo assets engineering, 2017, vol. 328, no. 10, pp. 50-58. In Rus.

8. Aleroev A.A., Kondratiev S.A., Sharafayev R.R., Novokreshchennykh D.V., Zhigalov V.A. Carrying proppant fracturing low permeability reservoirs in the oil fields of the German autonomous region. Oil Industry, 2017, no. 9, pp. 108-111. In Rus.

9. Amir Ghaderi, Jaber Taheri-Shakib, Mohamad Amin Sharifnik. The effect of natural fracture on the fluid leak-off in hydraulic fracturing treatment. Petroleum, March 2019, vol. 5, Iss. 1, pp. $85-89$.

10. Jianming He, Chong Lin, Xiao Li, Yixiang Zhang, Yi Chen. Initiation, propagation, closure and morphology of hydraulic fracturing in sandstone cores. Fuel, 15 November 2017, vol. 208, pp. 65-70.

11. Mirzadzhanzade A.Kh. Tekhnologiya $i$ tekhnika dobychi nefti [Technology and technique of oil production]. Moscow, Nedra Publ., 1986. 382 p. 
12. Chukwudi Chukwudozie, Blaise Bourdin, Keita Yoshioka. A variational phase-field model for hydraulic fracturing in porous media. Computer Methods in Applied Mechanics and Engineering, 15 April 2019, vol. 347, pp. 957-982.

13. HanYi Wang, Mukul M. Sharma. Modeling of hydraulic fracturing closure on proppants with proppant settling. Journal of Petroleum Science and Engineering, December 2018, vol. 171, pp. 636-645.

14. Yew Kwang Yong, Maulianda Belladonna, Sia Chee Wee, Mohshim Dzeti, Eaton David. Determination of stimulated reservoir volume and anisotropic permeability using analytical modelling of microseismic and hydraulic fracturing parameters. Journal of Natural Gas Science and Engineering, October 2018, vol. 58, pp. 234-240.

15. Lei Li, Jingqiang Tan, Wood D.A., Zhengguang Zhao, Haichao Chen. A review of the current status of induced seismicity monitoring for hydraulic fracturing in unconventional tight oil and gas reservoirs. Fuel, April 2019, vol. 242, pp. 195-210.

16. Wei Fu, Savitski A.A., Damjanac B., Bunger A.P. Threedimensional lattice simulation of hydraulic fracturing interaction with natural fractures. Computers and Geotechnics, March 2019, vol. 107, pp. 214-234.

17. Ibragimov L.Kh., Mishchenko I.T., Cheloyants D.K. Intensifikatsiya dobychi nefti [Intensification of oil production]. Moscow, Nauka Publ., 2000. 414 p.

18. Muslim R.H. Nefteotdacha: proshloe, nastoyashchee, budushchee [Oil output: past, present, future]. Kazan, Fen Publ. House of the Academy of Sciences of the Republic of Tatarstan, 2014.750 p.

19. Nurgaliev R.Z., Gallyamov R.I., Makhmutov A.A., Kornev E.V., Astakhov A.V. Evaluation of the effectiveness of hydraulic fracturing taking into account the formed geological bodies. Geology, geophysics and development of oil and gas fields, 2017, no. 3, pp. 57-62. In Rus.

20. Debotyam Maity, Jordan Ciezobka. Using microseismic frequencymagnitude distributions from hydraulic fracturing as an incremental tool for fracture completion diagnostics. Journal of Petroleum Science and Engineering, May 2019, vol. 176, pp. 1135-1151.
21. Quanjie Zhu, Yu Feng, Ming Cai, Jinhai Liu, Honghui Wang. Interpretation of the extent of hydraulic fracturing for rockburst prevention using microseismic monitoring data. Journal of Natural Gas Science and Engineering, February 2017, vol. 38, pp. 107-119.

22. Nithin Manohar Rayudu, Xuhai Tang, Gaurav Singh. Simulating three-dimensional hydraulic fracturing propagation using displacement correlation method. Tunnelling and Underground Space Technology, March 2019, vol. 85, pp. 84-91.

23. Yuekun Xing, Guangqing Zhang, Tianyu Luo, Yongwang Jiang, Shiwen Ning. Hydraulic fracturing in high-temperature granite characterized by acoustic emission. Journal of Petroleum Science and Engineering, July 2019, vol. 178, pp. 475-484.

24. Yudin E.V., Gubanova A.E., Krasnov V.A. Method of assessing the interference of wells using the data of the technological modes of their operation. Oil industry, 2018, no. 8, pp. 64-69. In Rus.

25. Nurgaliev R.Z., Mukhliev I.R., Sagidullin L.R., Shchekaturova I.Sh., Rakhmatullin A.A. Peculiarities of the influence of well interference on the effect of hydraulic and gas-dynamic fracturing. Oilfield business, 2018, no. 3, pp. 29-34. In Rus.

26. Rastegaev A.V., Chernykh I.A., Ponomareva I.N., Martyushev D.A Assessment of the results of hydraulic fracturing based on a comprehensive analysis of microseismic monitoring data and geological and field information. Oil Industry, 2019, no. 8, pp. 122-125. In Rus.

27. Bo Zhang, Jiyang Liu, Wang S.G., Shucai Li, Weimin Yang. Impact of the distance between pre-existing fracture and wellbore on hydraulic fracturing propagation. Journal of Natural Gas Science and Engineering, September 2018, vol. 57, pp. 155-165.

28. Linkai Li, Hanqiao Jiang, Keliu Wu, Juniian Li, Zhangxin Chen. An analysis of tracer flowback profiles to reduce uncertainty in fracturenetwork geometries. Journal of Petroleum Science and Engineering, 2019, vol. 173, pp. 246-257.

29. Tarek A. Ganata, Meftah Hrairi. A new choke correlation to predict flow rate of artificially flowing wells. Journal of Petroleum Science and Engineering, 2018, vol. 171, pp. 1378-1389.

Received: 12 March 2020.

\section{Information about the authors}

Vladislav I. Galkin, Dr. Sc., professor, Perm National Research Polytechnic University.

Inna N. Ponomareva, Cand. Sc., assistant professor, Perm National Research Polytechnic University. Sergey S. Cherepanov, Cand. Sc., deputy general director, Geology and Development LLC LUKOIL-PERM. Evgeniy V. Filippov, head of the Department for Development of Oil and Gas Fields, LLC LUKOIL-PERM.

Dmitriy A. Martyushev, Cand. Sc., assistant professor, Perm National Research Polytechnic University. 